\title{
Sensory Q-Grader evaluation of fermented arabica coffees by yeast (Saccharomyces cerevisiae) and lactic bacteria (Pediococcus acidilactici) cultures
}

\author{
Sandy Dias Rodrigues ${ }^{1}$ (D), Vinicius Serafim Coelho ${ }^{\text {(iD), Valdeir Viana Freitas }}{ }^{2}$ (iD), Alessandra Brioschi ${ }^{1}$ (iD), Dério Brioschi Júnior ${ }^{1}$ (iD) \\ Rogério Carvalho Guarçoni ${ }^{3}$ (D) , Lucas Louzada Pereira1 ${ }^{\text {(D) }}$, Monique Renon Eller ${ }^{2}$ (D), Wilton Soares Cardoso ${ }^{1}$ (D)
}

${ }^{1}$ Instituto Federal do Espírito Santo, Venda Nova do Imigrante, ES, Brasil

${ }^{2}$ Universidade Federal de Viçosa/UFV, Viçosa, MG, Brasil

${ }^{3}$ Instituto Capixaba de Pesquisa Assistência Técnica e Extensão Rural/INCAPER, Domingos Martins, ES, Brasil

Contact authors: sandy19rdias@gmail.com, viniciusserafimcoelho16@gmail.com, valdeir.vianaf@gmail.com, alebrioschi@hotmail.com, derio.brioschi@outlook.com, rogerio.guarconi@gmail.com, lucas.pereira@ifes.edu.br, monique.eller@ufv.br, wilton.cardoso@ifes.edu.br

Received in December 6, 2019 and approved in September 8, 2020

\section{ABSTRACT}

The objective of this study was to evaluate sensorially, by professional Q-Grader, the beverage coffee from fermentation natural and fermentation with the use of yeasts and lactic acid bacteria as starter cultures in wet coffee processing. The Arabica coffee was harvested at two different altitudes in Espírito Santo State. Both coffees went through 04 treatments: inoculated with starter cultures Saccharomyces cerevisiae (YML) or Pediococcus acidilactici CCT 1622 (LAF), natural fermentation (NF) (not inoculated) and Control, without fermentation (WF). The coffee was processed by just the wet process. After process and roasting, the sensorial analysis was performed to understand the impact of fermentation processing in the coffee quality, and was performed by $6 \mathrm{Q}$-Graders, following SCA protocol. The study evidenced that the use of natural fermentation or starter cultures during post-harvest coffee contributed to obtain a quality beverage with pleasurable sensorial characteristics, punctuated by the tasters in the overall score obtained and also by the high sensory scores in attributes such as fragrance, acidity, aftertaste and the different perceived aromas. This work demonstrates for coffee growers that fermentation technology is not intuitive but requires an understanding of the relationship of the microorganisms with the coffee and the environment. In addition to the other chemical aspects of roasting and brew coffee.

Key words: Fermentation; Microorganisms; Quality.

\section{INTRODUCTION}

Coffee quality is strongly related to post-harvest processes. This sensorial variation is undoubtedly mostly related to changes in the chemical composition caused by the different post-harvest processes (Toledo et al., 2016).

The post-harvest is influenced by microbiota, mainly in fermentation processes. The condition of the environment; that is can lead to changes in internal metabolites, creating a stress condition, and consequently different conditions for the development of microorganisms (Pereira et al., 2018). Gonzalez-Rios, Suarez-Quiroza and Schorr-Galindoc (2007), Gloess et al. (2013) and Gloess et al. (2014) indicated that natural microbiome could provide a special condition to natural fermentation, that occurs during the wet process.

The fermentation in the wet process can be a relevant way to improve the beverage coffee (Lee et al., 2015). During fermentation, even just for mucilage withdrawal, many metabolites and enzymes are produced (Tai; Hsieh; Sheu, 2014; Bressani et al., 2018), and organic acids and other products of enzymes are secreted and may interfere with the final flavor of the beverage (Schwan; Silva; Batista, 2012; Silva, 2014). Some studies are trying to relate the fermentation with aromas and flavors in the coffee, and mainly to the gain of quality (Schwan; Silva; Batista, 2012; Silva, 2014; Lee et al., 2015).
According to Lee et al. (2015), some process includes the development of a methodology for the accurate determination of the endpoint of fermentation and the use of a relevant starter culture for the fermentation process. With the use of starter cultures, the fermentation goes beyond the removal of mucilage. It is use have been shown to be of great importance to produce fermented products, with the aim of obtaining products with differentiated sensorial quality (Martins et al., 2019). This process consists in the selection of microorganisms that are inoculated directly into the prepared material and which may predominate over the existing microbiota and promote desirable changes in the final product (Caplice; Fitzgerald, 1999). These processes can improve the quality of fermented foods, providing control and standardization of the final product (Tamang, 2014; Kwon, 2018).

In the post-harvest of the coffee, the fermentation with the use of culture starter microorganisms can promote change in the sensory profile. Silva et al. (2013) used aerobic mesophilic strains $B$. cereus, B. megaterium, B. subtillis, as well as some yeast strains $C$. parapsilosis, $P$. guilliermondiie e $S$. cerevisiae isolated from arabica coffee to verify the performance in the fermentation, and observed that all the inoculate studied stood out promising in the demuciling of coffee, thus improving the quality of the beverage. 
The fermentations were generally significant for the increase in quality, especially the fermentations with starter cultures. The use of yeasts has been widely publicized (Evangelista et al., 2014a, 2014b). Saccharomyces sp. have been used in the production of various drinks due to their ability to produce aromatic compounds during the fermentation process (Canonico et al., 2020; Olaniran et al., 2017).

Another point suggests that starter cultures can control the microorganism population avoiding for instance development of spoilage microorganisms that produce ochratoxin A (OTA), and improve coffee quality sensory through synthesis of aroma precursors (Massawe; Lifa, 2010).

The coffee sensorial analysis is the identification of flavors, aromas, taste of coffee beverages and follows strict protocols. This analysis is the most used determination method in the quantitative characterization process of the coffee, being the aroma, acidity, bitterness, body, flavor, sweetness and overall impression of the beverage the main sensorial attributes to be analyzed, since the coffee quality is defined by the intensity and balance of these attributes (Bicho et al., 2013; Tolessa et al., 2016). In this way, sensorial tests are performed to determine different characteristics among samples, by attribute notes and consequently determine the preference among similar products (Santos et al., 2012; Maurice, 2017).

It is necessary to evaluate the fermentation as a process besides the demuciling, but to generate a final product of a higher sensory quality, including the use of bark and pulp as other substrates to microorganisms. In this context, the main objective of the present study was to carry out the spontaneous fermentation, and others with starter cultures and evaluate the impact of this processing at the sensorial level by coffee Q-grader tasters.

\section{MATERIAL AND METHODS}

\subsection{Culture medium and chemicals}

The medium YEPD Broth and YEPD agar were purchased from Sigma-Aldrich Chemical Company (St. Louis, MO, USA). MRS Broth and MRS agar were purchased from Oxoid Ltda (Wade Road, UK).

Polysorbate from Sigma-Aldrich Chemical Company (St. Louis, MO, USA).

The extract malt type DME (Dry Malt Extract) Dry Brew were purchase from Liotécnica (Embu das Artes - SP - Brazil).

\subsection{Raw materials - harvest}

The coffee cherries of Catuaí Vermelho variety were harvested at the initial maturation stage at two rural properties in Espírito Santo - BR in mountain range: a $900 \mathrm{~m}$ farm in the city of Venda Nova do Imigrante - ES (geographic location $20^{\circ} 25^{\prime} 21.3$ 'S and $41^{\circ} 10^{\prime} 09.3$ ' $\mathrm{W}$ ), and another at $1200 \mathrm{~m}$, located in the city of Afonso Cláudio (geographical location $20^{\circ} 11^{\prime} 12.2^{\prime \prime} \mathrm{S}$ and $41^{\circ} 02^{\prime} 07.1$ 'W). Fruit collection was carried out from July to August 2017.

\subsection{Multiplication and activation of microorganisms}

The yeast $S$. cerevisiae JP14 was isolated from bee products and showed fermentative potential in honeybased musts (Silva et al., 2020). It was obtained from the microorganism's bank of the Laboratory of Biochemical and Fermentative Processes of the Department of Food Technology, Federal University of Viçosa. $50 \mu \mathrm{L}$ aliquots of a suspension containing this yeast were activated in liquid YEPD medium $(0.5 \% \mathrm{w} / \mathrm{v}$ yeast extract, $1 \% \mathrm{w} / \mathrm{v}$ peptone and $2 \% \mathrm{w} / \mathrm{v}$ dextrose) at $25^{\circ} \mathrm{C}$ for $12 \mathrm{~h}$. Approximately $20 \mathrm{~mL}$ of the suspension was placed in $1000 \mathrm{~mL}$ in the YEPD medium for multiplication until a concentration of approximately $10^{7}$ cells / $\mathrm{mL}$, checked by plating in YEPD agar.

About $50 \mu \mathrm{L}$ of lactic acid bacteria $P$. acidilactici CCT1622, from microorganism's bank of the Laboratory of Biochemical and Fermentative Processes of the Department of Food Technology, Federal University of Viçosa. The bacteria were activated in liquid MRS medium plus $0.1 \% \mathrm{w} / \mathrm{v}$ of $80 \%$ polysorbate, at $30{ }^{\circ} \mathrm{C}$ for approximately $12 \mathrm{~h} .10 \mathrm{ml}$ of this suspension was replaced in $500 \mathrm{ml}$ of the MRS culture medium until it reached a concentration of approximately $10^{7} \mathrm{CFU} / \mathrm{ml}$, checked by plating.

\subsection{Processing and fermentation}

There was a selection of the fruits in which the damaged grains and green coffees were discarded, not being used in the processing. It was harvested $20 \mathrm{~kg}$ of coffee cherries per experimental plot in both experiments. After harvest, the fruits were processed by the wet process.

The raw materials used in the formulated for fermentation were composed of: pulp/coffee husk, water, and inoculum of microorganisms (to fermentation with starter cultures). All treatments were carried out in 50-liter plastic drums at room temperature.

The following fermentation processing were performed:

a) Natural (Spontaneous) fermentation (NF): $2 \mathrm{~kg}$ of pulped cherry, $2 \mathrm{~kg}$ of husk/pulp and 2 liters of water, in the proportion 1: 1: 1;

b) Fermentation yeast and malt (hydrolytic enzymes) (YMF): $500 \mathrm{~mL}$ of YEPD culture medium with Saccharomyces cerevisiae JP14 at approximately $10^{7}$ cells $/ \mathrm{mL}, 2 \mathrm{~kg}$ of pulped cherry, $2 \mathrm{~kg}$ of the husk/pulp and $1 \% \mathrm{~m} / \mathrm{v}$ of extract malt type DME previously diluted in $2 \mathrm{~L}$ of water at $40^{\circ} \mathrm{C}$;

c) Lactic acid fermentation (LAF): $500 \mathrm{~mL}$ of MRS medium with lactic acid bacterium Pediococcus acidilactici 
CCT 1622 at approximately $10^{7}$ cells $/ \mathrm{mL}, 2 \mathrm{~kg}$ of pulped cherry, $2 \mathrm{~kg}$ of husk/pulp and $2 \mathrm{~L}$ of water;

d) Control (without fermentation - WF): $2 \mathrm{~kg}$ of pulped cherry went to drying, direct, without fermentation.

The fermentations were carried out outside the Coffee Analysis and Research Laboratory - LAPC, of the Federal Institute of Espírito Santo (IFES), Campus Venda Nova do Imigrante, for $24 \mathrm{~h}$.

\subsection{Experimental designer}

Experiments at 900 and $1200 \mathrm{~m}$ altitudes were conducted in a randomized complete block design with three replicates and four treatments, one without fermentation, Natural Fermentation (without starter cultures), and two with starter cultures for arabica coffee fermentation: Malting and Yeast Fermentation, and Fermentation with Lactic Bacteria.

\subsection{Sensory analysis - SCA protocol}

The cupping form provides the possibility of evaluating eleven (11) important attributes for coffee: Fragrance/Aroma, Uniformity, Absence of Defects (Clean Cup), Sweetness, Flavor, Acidity, Body, Aftertaste, Balance, Defects and Overall evaluation. Highly positive results arise from the perception of a balanced group formed by the evaluated attributes.

The sensory analysis of the coffees was carried out by 6 (six) tasters, all with Q-Graders certification. The minimum number of evaluators in sensory analysis was initially proposed by Pereira et al. (2018), aiming at reducing the subjectivity process of the analysis.

\subsection{Preparation of samples for roasting and cupping}

For the sensory evaluation, coffee samples were prepared in the coffee sensory analysis laboratory (LAPC) of the Federal Institute of Espírito Santo, city of Venda Nova do Imigrante, Brazil, following the methodology of the Specialty Coffee Association (SCA). The coffee samples roasting processes were carried out using the Laborato TGP2 roaster and monitored with Agtron-SCA disk array. The roasting point of the samples was between the colors of discs \# 55 and \# 65 (Specialty Coffee Association of American - SCAA, 2013).

The roasting process was carried out 24 hours in advance (on each day of the experiment) and the grinding respected the time of 8 hours of rest after the 24 hours of roasting. The samples were roasted according to the roasting routine established by the LAPC, with an initial temperature of $150{ }^{\circ} \mathrm{C}$ (setpoint). The temperature was raised with an increase of $5{ }^{\circ} \mathrm{C}$ per minute until reaching $200{ }^{\circ} \mathrm{C}$. The samples were cooled for 1 minute; after that, the airflow cycle remained constant at $50 \%$ of the total capacity of the Laboratto TGP2 roaster. All samples were roasted for 9 to 11 minutes and, after roasting and cooling, the samples remained sealed, according to the methodology established by the SCA. The coffee samples were ground with a Bunn G3 electric grinder, with medium grain size. Each sample had 5 cups, and 8.25 grams of ground coffee was used in $150 \mathrm{ml}$ of water, according to the midpoint of the optimal balance graph for the Golden Cup (SCAA, 2013). To define the coffee standards, the quality scale of the SCAA (2013) was adopted, which describes the following definition: 70.25 to 79.75 Very Good Coffee -80.00 to 89.75 - excellent and above 90.00 outstanding. Although the Quality Scale of SCAA sets a coffee with averages of 70.25 to 79.75 as very good coffee, that same coffee is not framed as special.

\subsection{Statistical analyzes}

All statistical analyses were performed using experimental results were expressed as means of three parallel repetitions. ANOVA and Tukey test analyses were performed using $\mathrm{P}$ values $<0.05$ was regarded as significant.

The multivariate analysis was carried out with averages of 5\% probability, followed by analysis of the main components to group the treatments, using visual exams in graphical dispersions for the experiments 900 and 1200 meters of altitude, an accumulated variability above $70 \%$ is suitable for its accomplishment. For the statistical analysis, the GENES program (Cruz, 2015) was used.

\section{RESULTS AND DISCUSSION}

All sensory processes involved a standardized series of steps that prescribe the handling and preparation of the sample and methodology to sensory evaluation of a sample of each coffee ( 03 repetition for treatment) by 6 Q-graders. Sensory evaluation included the following coffee characteristics or attributes: Fragrance, Aroma, Aftertaste, Body, Acidity, Clean Cup, Uniformity, Sweetness, Balance and Overall (with scores of 7 - 10), and the Final or Global Score (50 -100, the result of the sum of all attributes).

The sensorial results of the experiments are presented in Tables $1-4$, showing the mean values of the sensorial attributes by treatment, and by altitude, statistic evaluable with Tukey test at 5\% probability. The score final, everyone coffees were classified as specialty coffees by the SCAA protocol (SCAA, 2013).

Attributes like Clean Cup, Uniformity, and Sweetness were evaluable but everyone samples received only the score 10 , and they did not present statistically significant differences. These attributes not be shown in the tables, but your values were added to the Global score.

Table 1 shows the statistical analysis for Fragrance and Flavor from notes of the panel. 
Table 1: Averages of the characteristics of Fragrance and Flavor evaluated in four treatments and in two environments (altitudes).

\begin{tabular}{|c|c|c|c|c|c|c|c|c|c|c|c|c|}
\hline & \multicolumn{6}{|c|}{ Fragrance } & \multicolumn{6}{|c|}{ Flavor } \\
\hline \multirow{2}{*}{ Treatments } & \multicolumn{12}{|c|}{ Altitudes } \\
\hline & \multicolumn{3}{|c|}{$900 \mathrm{~m}$} & \multicolumn{3}{|c|}{$1200 \mathrm{~m}$} & \multicolumn{3}{|c|}{$900 \mathrm{~m}$} & \multicolumn{3}{|c|}{$1200 \mathrm{~m}$} \\
\hline Control, without fermentation - WF & 7.20 & $\mathrm{a}$ & $\mathrm{B}$ & 7.45 & $\mathrm{a}$ & A & 7.35 & $\mathrm{a}$ & $\mathrm{B}$ & 7.75 & $\mathrm{a}$ & A \\
\hline Natural fermentation $-\mathrm{NF}$ & 7.43 & $\mathrm{a}$ & A & 7.23 & $\mathrm{a}$ & $\mathrm{A}$ & 7.63 & $\mathrm{a}$ & A & 7.47 & $\mathrm{ab}$ & A \\
\hline Yeast/malt fermentation - YMF & 7.45 & $\mathrm{a}$ & A & 7.23 & $\mathrm{a}$ & A & 7.57 & $\mathrm{a}$ & A & 7.38 & $\mathrm{~b}$ & A \\
\hline Lactic acid fermentation LAF & 7.35 & $\mathrm{a}$ & A & 7.35 & a & $\mathrm{A}$ & 7.60 & $\mathrm{a}$ & A & 7.43 & $\mathrm{ab}$ & A \\
\hline
\end{tabular}

${ }^{1}$ Means followed by at least one same horizontal capital letter and at least one same lowercase vertical letter does not differ from each other by the Tukey test at $5 \%$ probability.

Fragrance is the volatile compounds from freshly ground roasted coffee, and Flavor is the volatile compounds with liquid composts from freshly brewed coffee. The fragrance is the result of a complex mixture of volatile compounds (Vitzthum, 1999; Bröhan et al., 2009).

The Flavor has influence direct of the taste and aroma. The flavor characteristic of coffee is due to the presence and contents of various volatile chemical constituents, among which are acids, aldehydes, ketones, sugars, proteins, amino acids, fatty acids, phenolic compounds, among others. Flavor is often related to taste because our taste buds are located in the mouth, but in fact, the flavor is linked to all senses, especially smell.

The aroma (fragrance) is the one of most important coffee attributes, and it is largely depending on the species, climatic and soil conditions, cultivation, and post-harvest storage yet depends of roasting conditions (Marek et al., 2020). By The final aroma is result of reactions of decomposition of non-volatile compounds contained in raw coffee, i.e., pyrolysis, caramelization, and Maillard reactions (Nooshkam; Varidi; Bashash, 2019).

The aroma (fragrance) of rousted and ground coffee is the result of the over 850 volatile compounds like hydrocarbons, alcohols, aldehydes, ketones, acids and anhydrides, esters, lactones, phenols, furans and pyrans, thiophenes, pyrroles, oxazoles, thiazoles, pyridines, pyrazines, and other nitrogenous and sulfurous compounds (Grosch, 2001). The roasting conditions can affect the aromatic profile of roast beans by hampering the complex balance of these volatiles and their intermolecular interactions (Nagaraju; Bhattacharya, 2010). After roasting, the aroma of the bean still be influenced by storage, grinding and also the extraction. The storage and grinding must to equilibrate the moisture and aromatics balance and to increase the bean surface area exposed to extraction or brewing, respectively (Akiyama et al., 2003).

The Fragrance indicated that just altitude impacted the final quality when we compare the averages for without fermentation WF. Fragrance results correlate with those of Bosselmann et al. (2009), who concluded that the fragrance was significantly affected by the altitude with increased fragrance at higher altitudes. The samples of WF at $900 \mathrm{~m}$ showed lower scores than WF $1200 \mathrm{~m}$.

In the attribute Flavor, the results show that WF (control) was affected by altitude again. Evaluating the Flavor in the same altitude, the fermented samples did not differ from the control to $900 \mathrm{~m}$. For $1200 \mathrm{~m}$, the YMF samples presented a lower average than the control.

Basically, except for YMF samples of $1200 \mathrm{~m}$, there were no significant differences of the notes within the same altitude, we can infer that the fermentation did not alter the notes of Flagrance and Aroma attributes. However, authors as Evangelista et al. (2014a, 2014b) observed that the use of starter cultures, yeasts, in coffee cherries processed by natural or dry process produced coffee beverages with a distinctive flavor and is an interesting alternative for obtaining a beverage quality.

Although we do not have a difference in notes, the fermented cafes presented different aromas in relation to control. As an example (data not shown), the aromas and flavors description related by a taster in relation to the coffees of $900 \mathrm{~m}$ follows: WF - sweet / honey / spices; NF - Floral / citric acid orange / wine / liqueur / sweet / spices; YMF toasted almond / light fruity / wine / liqueur / brow sugar; LAF - milk chocolate / floral / wine / caramel / sweet / honey / orange acidity.

Table 2 about Acidity and Body's coffee, follow below.

The acidity is very important for the quality of coffee and beverages made from roasted Arabica coffee beans are characterized by high acidity and fruity aroma (Dong et al., 2015). By result, should highlight that control WF $900 \mathrm{~m}$ got low notes for this characteristic, and it's possible to observe that all fermented coffees improved the note in relation to control. However, the $1200 \mathrm{~m}$ coffee YMF receives a lower note this attribute when compared to control (WF), at 5\% probability by the Tukey test (Table 2 ). 
Table 2: Average of Acidity and Body evaluated in four treatments and in two environments (altitudes).

\begin{tabular}{|c|c|c|c|c|c|c|c|c|c|c|c|c|}
\hline & \multicolumn{6}{|c|}{ Acidy } & \multicolumn{6}{|c|}{ Body } \\
\hline \multirow{2}{*}{ Treatments } & \multicolumn{12}{|c|}{ Altitudes } \\
\hline & \multicolumn{3}{|c|}{$900 \mathrm{~m}$} & \multicolumn{3}{|c|}{$1200 \mathrm{~m}$} & \multicolumn{3}{|c|}{$900 \mathrm{~m}$} & \multicolumn{3}{|c|}{$1200 \mathrm{~m}$} \\
\hline Control, without fermentation - WF & 7.05 & $\mathrm{~b}$ & $\mathrm{~B}$ & 7.70 & $\mathrm{a}$ & $\mathrm{A}$ & 7.30 & $\mathrm{a}$ & $\mathrm{A}$ & 7.35 & $\mathrm{a}$ & A \\
\hline Natural fermentation $-\mathrm{NF}$ & 7.48 & $\mathrm{a}$ & A & 7.28 & $\mathrm{ab}$ & A & 7.55 & $\mathrm{a}$ & A & 7.25 & $\mathrm{a}$ & $\mathrm{B}$ \\
\hline Yeast/malt fermentation - YMF & 7.45 & $a b$ & A & 7.23 & $\mathrm{~b}$ & A & 7.40 & $\mathrm{a}$ & A & 7.23 & $\mathrm{a}$ & A \\
\hline Lactic acid fermentation - LAF & 7.43 & $a b$ & A & 7.38 & $a b$ & A & 7.45 & $\mathrm{a}$ & A & 7.32 & $\mathrm{a}$ & $\mathrm{A}$ \\
\hline
\end{tabular}

${ }^{1}$ Means followed by at least one same horizontal capital letter and at least one same lowercase vertical letter does not differ from each other by the Tukey test at $5 \%$ probability.

Acidity in coffee has been the subject of several scientific controversies. The results indicate that the acidity is different regardless of the type of processing. This suggests that the metabolic processes generated during the fermentation phase in the methods used in the experiments had a significant effect on the production of some compounds that confer a higher acidity load on coffee. The presence of organic acids during fermentation may be due to coffee composition, such as citric acid, or may be associated with the metabolism of the microorganisms (Silva et al., 2013) however, this increase in acidity will impact the acceptability of the beverage, either positively or negatively, depending on the acid and its concentration (Evangelista et al., 2014b).

The Body is a sensory perception of the "weight" of the beverage on the tongue. A high Body score may be perceived as a defect in some cases, especially for low-altitude coffees (Avelino et al., 2005). The results in Table 2 did not present statistical differences between the processes in the altitude range, only there were statistical differences between the NF coffees from 900 and $1200 \mathrm{~m}$ (capital letters in line), at $5 \%$ of probability by Tukey test.

In Table 3, Balanced coffee or high Balance score may be a complex beverage but this does not signify the coffee have an overwhelming flavor or aroma characteristics. For attribute Balance in the range of $900 \mathrm{~m}$, the average scores of YMF process presented a statistical difference at $5 \%$ probability in relation to the WF and LAF method, but it does not differ from the NF method. In the $1200 \mathrm{~m}$ range, the methods do not present statistical difference between them. Comparing between altitude (capital letters), the YMF method presented a statistical difference, again indicating the altitude effect in the process (Table 3).

The fermentation process improved the note for all treatments of the coffee of $900 \mathrm{~m}$ in the Balance score. Assessing between altitudes, there weren't a statistical difference of $900 \mathrm{~m}$ and $1200 \mathrm{~m}$ coffees each treatment, except for the YMF fermentations, with $900 \mathrm{~m}$ get superior score.

The Aftertaste is the taste of brewed coffee vapors released after swallowing. Also called "finish". The sensorial characteristic Aftertaste, the results at $900 \mathrm{~m}$ indicate that the NF processing presents a statistical difference of the WF process with $5 \%$ of probability, however, it does not differ from the others. To the range of $1200 \mathrm{~m}$, the methods do not present differences between them. When comparing the altitudes, the WF at $1200 \mathrm{~m}$ with a higher average, and NF at $1200 \mathrm{~m}$, with a lower average, to $900 \mathrm{~m}$ similar processes, presents a statistical difference at a $5 \%$ probability by the Tukey test.

For the Aftertaste attribute, the fermentation improved the cafes of $900 \mathrm{~m}$, including allowing this NF coffees to obtain a higher note than the coffees of NF of range $1200 \mathrm{~m}$.

The attribute Overall is very relevant, manly for fermented coffee, that in the most of time, it showed different aromas and flavors, and it is important that coffee has been analyzed in whole (Table 4). To Poltronieri and Rossi (2016), the overall score is based on the flavor experience of the individual "cupper" as a personal appraisal. For SCAA protocol (2013), explains that this attribute should reflect the integrated classification of the sample, as perceived by the individual panel.

The scores of NF and YMF samples at $900 \mathrm{~m}$ range were upper than WF and LAF. It is the first attribute that LAF got a score lower than treatments. For $1200 \mathrm{~m}$, in the same column, there were no differences among treatments.

In relation to altitudes, it is highlighting that YMF 900 $\mathrm{m}$ showed a superior average in relation to YMF $1200 \mathrm{~m}$.

The Final or Global Score is calculated by summing the individual scores given for each of the primary attributes. The Global score has proven to be a meaningful way to describe the range of coffee quality. Global Score Quality Classification:

- 90-100 - Outstanding - Specialty

- 85-99.99 - Excellent - Specialty

- 80-84.99 - Very Good - Specialty

- $\quad<80.0$ - Below Specialty Quality - Not Specialty

Based on Global score (Table 4), all coffees were classified like very good, specialty coffees.

When compared within the same altitude, in $900 \mathrm{~m}$ the WF presented a lower sensory result, but in the $1200 \mathrm{~m}$ range not present statistical difference among samples. 
Table 3: Averages of Overall and Aftertaste evaluated in four treatments and in two environments (altitudes).

\begin{tabular}{|c|c|c|c|c|c|c|c|c|c|c|c|c|}
\hline \multirow{3}{*}{ Treatments } & \multicolumn{6}{|c|}{ Balance } & \multicolumn{6}{|c|}{ Aftertaste } \\
\hline & \multicolumn{12}{|c|}{ Altitudes } \\
\hline & \multicolumn{3}{|c|}{$900 \mathrm{~m}$} & \multicolumn{3}{|c|}{$1200 \mathrm{~m}$} & \multicolumn{3}{|c|}{$900 \mathrm{~m}$} & \multicolumn{3}{|c|}{$1200 \mathrm{~m}$} \\
\hline Control, without fermentation - WF & 7.10 & $\mathrm{~b}$ & A & 7.35 & $\mathrm{a}$ & A & 7.00 & $\mathrm{~b}$ & $\mathrm{~B}$ & 7.30 & $\mathrm{a}$ & A \\
\hline Natural fermentation - NF & 7.47 & $\mathrm{ab}$ & A & 7.28 & $\mathrm{a}$ & A & 7.33 & $\mathrm{a}$ & A & 7.05 & $\mathrm{a}$ & $\mathrm{B}$ \\
\hline Yeast and malt fermentation - YMF & 7.80 & $\mathrm{a}$ & A & 7.43 & $\mathrm{a}$ & $\mathrm{B}$ & 7.25 & $a b$ & A & 7.10 & $\mathrm{a}$ & A \\
\hline Lactic acid fermentation - LAF & 7.37 & $\mathrm{ab}$ & A & 7.37 & $\mathrm{a}$ & A & 7.18 & $\mathrm{ab}$ & A & 7.12 & $\mathrm{a}$ & A \\
\hline
\end{tabular}

${ }^{1}$ Means followed by at least one same horizontal capital letter and at least one same lowercase vertical letter does not differ from each other by the Tukey test at $5 \%$ probability.

Table 4: Averages of Overall and Global score evaluated in four treatments and in two environments (altitudes).

\begin{tabular}{|c|c|c|c|c|c|c|c|c|c|c|c|}
\hline \multirow{3}{*}{ Treatments } & \multicolumn{6}{|c|}{ Overall } & \multicolumn{5}{|c|}{ Global } \\
\hline & \multicolumn{6}{|c|}{ Altitude } & \multicolumn{5}{|c|}{ Altitude } \\
\hline & \multicolumn{3}{|c|}{$900 \mathrm{~m}$} & \multicolumn{3}{|c|}{$1200 \mathrm{~m}$} & \multicolumn{2}{|l|}{$900 \mathrm{~m}$} & \multicolumn{3}{|c|}{$1200 \mathrm{~m}$} \\
\hline Control, without fermentation - WF & 7.10 & $\mathrm{~b}$ & $\mathrm{~B}$ & 7.55 & $\mathrm{a}$ & A & $80.10 \quad b$ & $\mathrm{~B}$ & 82.45 & $\mathrm{a}$ & A \\
\hline Natural fermentation $-\mathrm{NF}$ & 7.47 & $a b$ & A & 7.38 & $\mathrm{a}$ & A & $82.13 \mathrm{ab}$ & A & 80.95 & $\mathrm{a}$ & A \\
\hline Yeast/malt fermentation - YMF & 7.52 & $\mathrm{a}$ & A & 7.20 & $\mathrm{a}$ & $\mathrm{B}$ & $82.43 \quad \mathrm{a}$ & A & 80.62 & $\mathrm{a}$ & $\mathrm{B}$ \\
\hline Lactic acid fermentation LAF & 7.43 & $\mathrm{~b}$ & A & 7.40 & $\mathrm{a}$ & A & $81.55 \mathrm{ab}$ & A & 81.37 & $\mathrm{a}$ & A \\
\hline
\end{tabular}

${ }^{1}$ Means followed by at least one same horizontal capital letter and at least one same lowercase vertical letter does not differ from each other by the Tukey test at $5 \%$ probability.

The fermented coffee of $900 \mathrm{~m}$ got upper than WF control, and they already showed notes statistic equal or superior (YMF) at coffee $1200 \mathrm{~m}$. In this column of $1200 \mathrm{~m}$, every fermented coffee has been statistically the same score in relation of WF control.

Although the altitude is indicated as a factor of influence of the quality of the coffee, many of the attributes evaluated sensorially it is noticed that the fermented cafes of $900 \mathrm{~m}$ obtained statistically equal notes to the fermented ones coming from $1200 \mathrm{~m}$, which did not happen for unfermented control coffees. The coffees from $1200 \mathrm{~m}$ presented the most sensorial characteristics with the highest grade. That is a significant improvement in quality for low altitude coffee.

Table 5 shows the eigenvalues and simple and cumulative percentages of the total variance of the main components of the experiment $900 \mathrm{~m}$ altitude.

Table 5: Main components and their respective eigenvalues and simple and cumulative percentages of the total variance of the experiment $900 \mathrm{~m}$ altitude.

\begin{tabular}{cccc}
\hline $\begin{array}{c}\text { Principal } \\
\text { Component }\end{array}$ & Eigenvalues & $\begin{array}{c}\text { Simple } \\
\text { percentage }\end{array}$ & $\begin{array}{c}\text { Cumulative } \\
\text { percentage }\end{array}$ \\
\hline CP1 & 10.99131 & 99.92 & 99.92 \\
CP2 & 0.005718355 & 00.05 & 99.97 \\
\hline
\end{tabular}

In Figure 1, it can be observed in the dispersion of the treatments based on the respective coordinates relative to the first two main components, CP1 and CP2, that the treatments Natural Fermentation - NF, Yeasts and Malt Fermentation YMF and Lactic Acid Bacteria Fermentation - LAF form a group, and Control another group, and that the two components absorbed $99.97 \%$ (Table 5) of the variation in the original characteristics.

The results indicated that fermentation could provide different sensorial attributes for the coffees, these behavior shows the new perspective for low altitude farms, to change the quality and provide new sensorial routes. The technologies that improve the quality of coffee can be implemented at different stages of production, from the coffee processing up to the storage. The presence of different microorganisms during coffee fermentation interferes with the final characteristics of the beverage (Ribeiro et al., 2017).

In Figure 2, it can be also observed in the dispersion of the treatments based on the respective coordinates relative to the first two main components, $\mathrm{CP} 1$ and $\mathrm{CP} 2$, that the treatments Natural Fermentation - NF, Yeasts and Malt Fermentation - YMF and Lactic Acid Bacteria Fermentation - LAF form a group, and Control another group, and that the two components absorbed $99.99 \%$ (Table 6 ) of the variation in the original characteristics. 


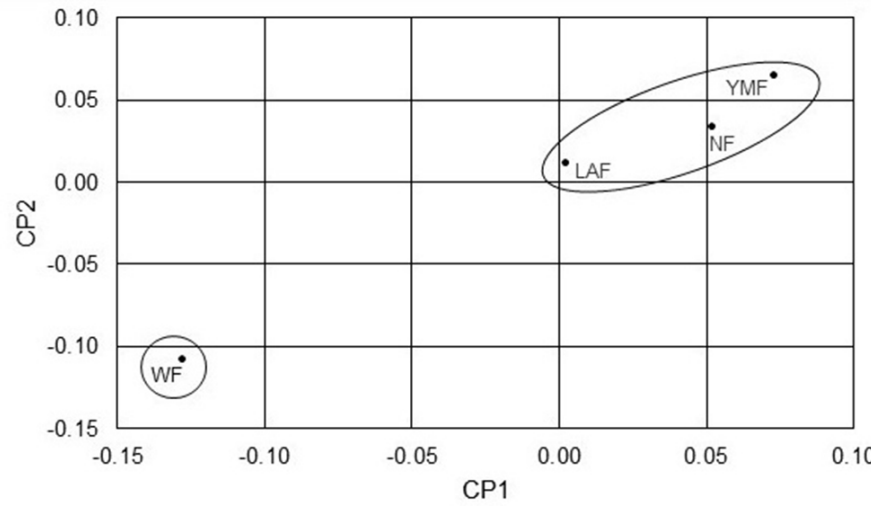

Figure 1: Diagram of dispersion about the first two main components of the treatments: Control, Natural Fermentation - NF, Yeasts and Malt Fermentation - YMF and Acid Bacteria Fermentation - LAF, of the experiment $900 \mathrm{~m}$ altitude.

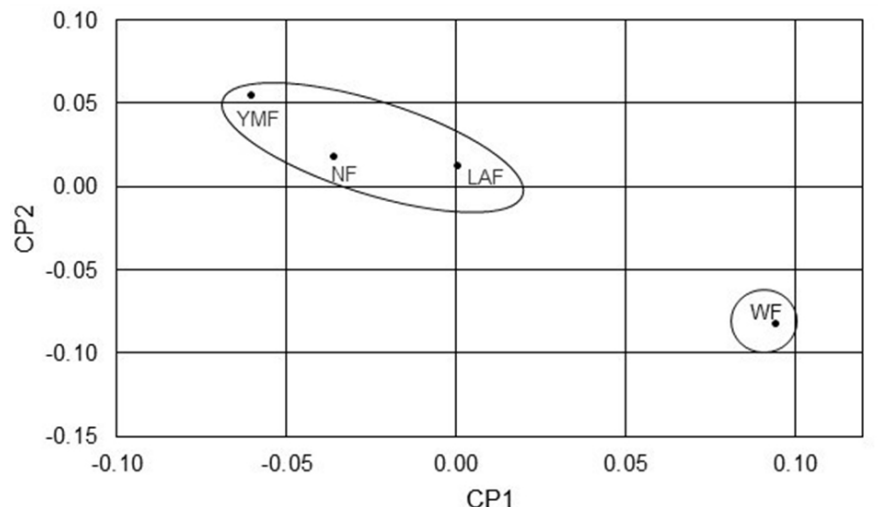

Figure 2: Diagram of dispersion in relation to the first two main components of the treatments: Control, Natural Fermentation - NF, Yeasts and Malt Fermentation - YMF and Acid Bacteria Fermentation - LAF, of the experiment $1200 \mathrm{~m}$ altitude.

Table 6: Principal components and their respective eigenvalues and simple and cumulative percentages of the total variance of the experiment $1200 \mathrm{~m}$ altitude.

\begin{tabular}{cccc}
\hline $\begin{array}{c}\text { Principal } \\
\text { Component }\end{array}$ & Eigenvalues & $\begin{array}{c}\text { Simple } \\
\text { percentage }\end{array}$ & $\begin{array}{c}\text { Cumulative } \\
\text { percentage }\end{array}$ \\
\hline CP1 & 10.99551 & 99.96 & 99.96 \\
CP2 & 0.003480997 & 0.0317 & 99.99 \\
\hline
\end{tabular}

These analyzes of key components, confirm that there is a differentiation between fermented and unfermented coffees. An individual analysis of samples realizes an improvement in the quality of coffees, mainly low altitude coffee trees, and none or some decrease in the quality of coffees from a higher altitude.

For the range of $1200 \mathrm{~m}$, wherever the statistical data in Table 1 - 4 did not present difference, the Global score of fermented coffees got lower than control. But in Figure 2, multivariate analysis, WF control stayed separated them, and presented an upper score.
For coffee processing, further research is needed to increase the understanding of the microbial ecology, physiology, and biochemistry of fermentation and how this scientific knowledge contributes to the development of coffee beverage character (Pereira et al., 2014). Further studies on the potential of different microorganisms should be evaluated in determining the quality of the beverage.

\section{CONCLUSIONS}

Sensorially the fermentation was significant for raise scores of coffees about the $900 \mathrm{~m}$ range. However, for the treatments applied to coffees of $1200 \mathrm{~m}$, as the fermented ones were not satisfactory, and despite statistically equal notes, in the evaluations by Tukey, in a joint evaluation, with the use of a multivariate analysis of principal components, it can be affirmed that the realized fermentations diminished the note of the cafes of $1200 \mathrm{~m}$ of altitude. The notes were not enough for loss of quality and change the classification level within the SCAA protocol (SCAA, 2013), but to a certain extent, it should be to realize further studies the effect of fermentation of coffee with potentially quality, like ones of high altitudes.

\section{ACKNOWLEDGMENTS}

The authors are thank to the Instituto Federal do Espírito Santo and Fundação de Amparo à Pesquisa e Inovação do Espírito Santo (FAPES) (Grant/ Award Number: 737/2016), for the financial support.

\section{REFERENCES}

AKIYAMA, M. Characterization of headspace aroma compounds of freshly brewed arabica coffees and studies on characteristic aroma compounds of ethiopian coffee. Journal of Food Science, 73(5):335-346, 2008.

AVELINO, J. Effects of slope exposure, altitude and yield on coffee quality in two altitude terroirs of Costa Rica, Orosi and Santa María de Dota. Journal of the Science of Food and Agriculture, 85(11):1869-1876, 2005.

BOSSELMANN, A. S. et al. The influence of shade trees on coffee quality in small holder coffee agroforestry systems in southern Colombia. Agriculture, Ecosystems and Environment, 129(1-3):253-260, 2009.

$\mathrm{BICHO}, \mathrm{N}$. C. et al. Impact of roasting time on the sensory profile of Arabica and Robusta coffee. Ecology of Food and Nutrition, 52(2):163-177, 2013.

BRESSANI, A. P. P. et al. Characteristics of fermented coffee inoculated with yeast starter cultures using different inoculation methods. Food Science and Technology, 92:212-219, 2018. 
BRÖHAN, M. et al. Influence of storage conditions on aroma compounds in coffee pads using static headspace GCMS. Food Chemistry, 116(2):480-483, 2009.

CANONICO, L. et al. Evolution of aromatic profile of Torulaspora delbrueckii mixed fermentation at microbrewery plant. Fermentation, 6(7):1-9, 2020.

CAPLICE, E.; FITZGERALD, G. F. Food fermentations: Role of microorganisms in food production and preservation. International Journal of Food Microbiology, 50(1):131-149, 1999.

CRUZ, C. D. GENES - a software package for analysis in experimental statistics and quantitative genetics. 2015. Versão Windows Viçosa: UFV. Available in: <www.ufv. br/dbg/genes/genes.htm>. Access in: October, 7, 2020.

DONG, W. J. et al. Characterization of fatty acid, amino acid and volatile compound compositions and bioactive components of seven coffee (Coffea robusta) cultivars grown in Hainan province, China. Molecules, 20:1668716708, 2015.

EVANGELISTA, S. R. et al. Inoculation of starter cultures in a semi-dry coffee (Coffea arabica) fermentation process. Food Microbiology, 44(87):95, 2014a.

EVANGELISTA, S. R. et al. Improvement of coffee beverage quality by using selected yeasts strains during the fermentation in dry process. Food Research International, 61:183-195, 2014b.

GLOESS, A. N. et al. Evidence of different flavor formation dynamics by roasting coffee from different origins: Online analysis with PTR-ToF-MS. International Journal of Mass Spectrometry, 365-366:324-337, 2014.

GLOESS, A. N. et al. Comparison of nine common coffee extraction methods: instrumental and sensory analysis. European Food Research and Technology, 236: 607$627,2013$.

GONZALEZ-RIOS, O.; SUAREZ-QUIROZA, M. L.; SCHORR-GALINDOC, S. Impact of "ecological” postharvest processing on coffee aroma: II. Roasted coffee. Journal of Food Composition and Analysis, 20(34):297-307, 2007.

GROSCH, W. Coffee: Recent developments. In: GROSCH, W. Chemistry III: Volatile compounds. Edited by Clarke RJ, Vitzthum OZ. Oxford: Blackwell Science, p.68-89, 2001.

KWON, D. L. Scientific knowledge in traditional fermented foods. Journal of Ethnic Foods, 5(3):153-154, 2018.
LEE, L. W. et al. Coffee fermentation and flavor - An intricate and delicate relationship. Food Chemistry, 185:182-191, 2015.

MAREK, G. et al. Detection and differentiation of volatile compound profiles in roasted coffee arabica beans from different countries using an electronic nose and GC-MS. Sensors, 20(7):e2124, 2020.

MASSAWE, G. A.; LIFA, S. J. Yeasts and lactic acid bacteria coffee fermentation starter cultures. International Journal Postharvest Technology Innovation, 2(1):41-82, 2010.

O`SULLIVAN, M. G. Handbook for Sensory and Consumer-Driven New Product Development: Innovative Technologies for the Food and Beverage Industry. 1st Edition Food Science, Technology and Nutrition, Cambridge, United Kingdom. Woodhead Publishing, 2017, 370p.

MARTINS, P. M. M. et al. Production of coffee (Coffea arabica) inoculated with yeasts: Impact on quality. Journal of the Science of Food and Agriculture, 99(13):5638-5645, 2019.

NAGARAJU, V. D.; BHATTACHARYA, S. Roasting green coffee beans using spouted bed roaster: Changes in physical characteristics. Journal of Food Science \& Technology, 47(6):674-677, 2010.

NOOSHKAM, M.; VARIDI, M.; BASHASH, M. The Maillard reaction products as food-born antioxidant and antibrowning agents in model and real food systems (Review). Food Chemistry, 275:644-660, 2019.

OLANIRAN, A. O. et al. Flavour-active volatile compounds in beer: production, regulation and control. Journal of Institute of Brewing, 123(1):13-23. 2017.

PEREIRA, L. L. et al. Propositions on the optimal number of Q-Graders and R-Graders. Journal of Food Quality, 3285452,1-7, 2018.

PEREIRA, G. V. de M. et al. Isolation, selection and evaluation of yeasts for use in fermentation of coffee beans by the wet process. International Journal Food Microbiology, 188:60-66, 2014.

POLTRONIERI, P.; ROSSI, F. Challenges in specialty coffee processing and quality assurance. Challenges, 7(2):1-22, 2016.

RIBEIRO, L. S. et al. Behavior of yeast inoculated during semi-dry coffee fermentation and the effect on chemical and sensorial properties of the final beverage. Food Research. International. 92:26-32, 2017. 
SANTOS, K. M. et al. Classification of Brazilian Coffee using near-infrared spectroscopy and multivariate calibration. Analytical Letters, 45(7):774-781, 2012.

SCHWAN, R. F.; SILVA, C. F.; BATISTA, L. R. Coffee fermentation. In: HUI, Y. H. (Ed), Handbook of plantbased fermented food and beverage technology. Boca Raton, Flórida: CRC Press, p.677-690, 2012.

SILVA, C. F. Microbial Activity during Coffee Fermentation. In: SCHWAN, R. F.; FLEET, G. H. Cocoa and Coffee Fermentations. Boca Raton, Flórida: CRC Press, p.368423, 2014.

SILVA, C. F. et al. Evaluation of a potential starter culture for enhance quality of coffee fermentation. World Journal of Microbiology \& Biotechnology, 29(2):23547, 2013.

SILVA, M. S. et al. Selection of yeasts from beekeeping products for alcoholic beverage production. Brazilian Journal of Microbiology, 51:323-334, 2020.

SPECIALTY COFFEE ASSOCIATION OF AMERICAN - SCAA. Protocols. January, 23. 2013. Available in:
$<$ https://sca.coffee/research/protocols-best-practices $>$. Access in: September, 10, 2020.

TAI, E. S.; HSIEH, P. C.; SHEU, S. C. Effect of polygalacturonase and feruloyl esterase from Aspergillus tubingensis on demucilage and quality of coffee beans. Process Biochemistry, 49(8):1274-1280, 2014.

TAMANG, J. P. Biochemical and modern identification techniques: Microfloras of fermented foods. In: BATT, C.; TORTORELLO, M. A. Encyclopedia of food microbiology. Oxford: Elsevier Ltd, p.250-258, 2014.

TOLEDO, P. R. A. B. et al. Relationship between the different aspects related to coffee quality and their volatile compounds. Comprehensive Reviews in Food Science and Food Safety, 15(4):705-719, 2016.

TOLESSA, K. et al. Prediction of specialty coffee cup quality based on near infrared spectra of green coffee beans. Talanta, 150:367-374, 2016.

VITZTHUM, O. G. Thirty years of coffee chemistry research. In: TERANISHI, R.; WICK, E. L.; HORNSTEIN, I. Flavor chemistry: Thirty years of progress. New York: Kluwer/Plenum, p.117-134, 1999. 